\title{
Exploring the public value of streets in the context of rapid urbanization
}

\author{
Song hao ${ }^{1}$ \\ ${ }^{1}$ Jianghan University, Wuhan, China
}

\begin{abstract}
Urban street is an important form of urban space. It is the economic lifeline of the city, as well as the most public space that people use in daily life. City streets bears not only the flourished style of this region, but also embodies the unique style and taste of a city. Since China's reform and opening, economic development has maintaining a rapid growth momentum. The economic base determines the superstructure,so the scale of city population is facing a rapid expansion. The city is changing rapidly with the vigorous development of motor traffic. The traditional street space is faced with the situation of being nibbled away.Based on the concept of urban street and public space, this paper further analyzes the importance of paying attention to urban public life for achieving sustainable development, and then points out the importance of urban street space as an important carrier of public life in the context of rapid urbanization.By clarifying the important public value of urban streets, this paper draws the attention of a wide range of city government decision-makers and urban planners.
\end{abstract}

\section{Introduction}

Aristotle, one of the greatest philosophers, scientists and educators in the ancient history of the world, once exclaimed that people come to the city to live and stay in the city to live better. So, what is a city? What kind of charm should a city have to attract people to come and stay in the city?

In ancient China, the I Ching has this description and record: "The middle of the day is the market, to the people of the world, to gather the world's goods, trade and retreat, each in its place." In this way, the original city was born out of the need for material exchange and bartering, specifically the place where craftsmen and merchants lived and worked after three major social divisions, and was a settlement with the function of commodity exchange. People can take what they need here, and they can easily exchange their unused and surplus goods for goods they don't have, which is perhaps the biggest attraction of cities to attract people to live here in the first place.

So, is the city still attractive in modern society? The answer may be yes, as evidenced by the continuous urbanization process, but this cannot conceal the many problems that have emerged in modern cities during the urbanization process. The reasons for the emergence of these social problems should be multifaceted, and this paper focuses on the overemphasis on "efficiency first" in the process of rapid urbanization at the expense of other aspects such as "equity", which has led to a lack of adequate public life in urban societies and thus led to This has led to a lack of adequate public life in urban societies, resulting in problems such as moral degradation and social indifference.

\section{The social problems caused by rapid urbanization}

Since the industrial revolution in Britain in the 1860s, the urbanization process has gradually accelerated throughout the world under the promotion of industrialization, and after more than a century of development, the average urbanization rate of some developed countries in Europe and America has exceeded $85 \%$ as of 2019 .

In contrast, reviewing the urbanization process in China since the founding of the country, the urbanization rates of China for all years from 1949-2019 are summarized and plotted into the corresponding Northam curves (Fig.1). It can be seen through Fig.1 that China is still in the acceleration phase of urbanization since it entered the acceleration phase in $1998^{[1]}$.

\footnotetext{
$\overline{{ }^{*} \text { Corresponding author: balok@126.com }}$
} 


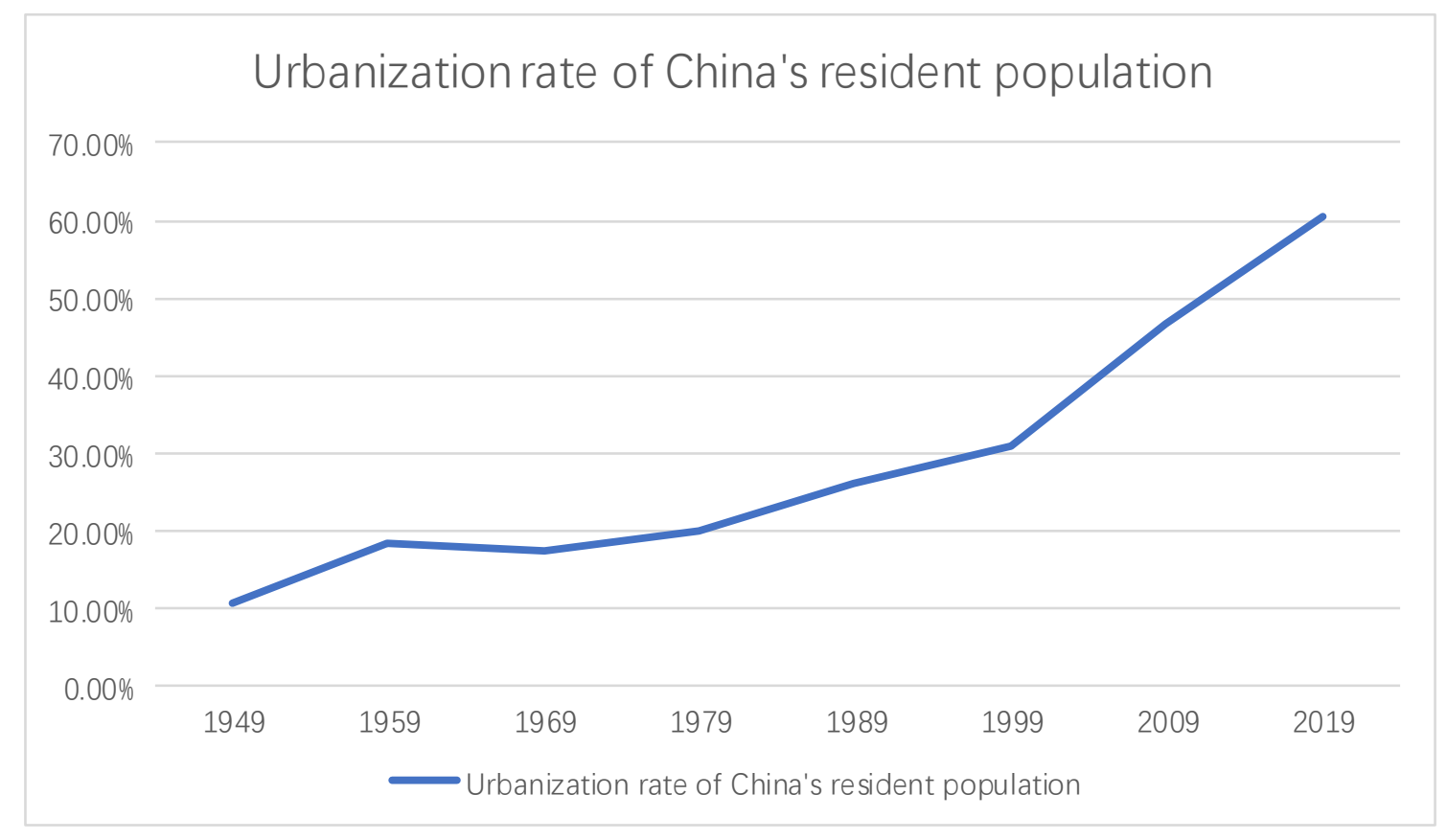

Fig.1. S-curve of urbanization in China

Due to the rapid urbanization rate and high construction intensity since the reform and opening up, and the core driving force of urbanization is economic development, the macro policies at the national level are mainly based on the idea of "prioritizing efficiency and taking into account equity", and the local governments only focus on GDP for a long time, which results in the lack of social equity, spiritual civilization construction, and environmental protection. This has led to the neglect of social equity, spiritual civilization and environmental protection, which has led to the deterioration of social morality, traffic congestion, environmental degradation and other social problems.

\section{Strategies for coping with urban social problems}

\subsection{Analysis of social problems}

\subsubsection{Analysis of social moral problems}

Although China has a relatively complete set of individual moral values under the influence of Confucianism, the construction of public morality, i.e. social morality, can be said to be very backward, which is summarized as a kind of " Individuals sweep the snow in front of the door, which cares about others on the frost on the tile" of the negative attitude towards social morality ${ }^{[2]}$. This is because the social ties between people at that time were mostly established by blood and local ties, and the main relationship between people was based on the ethical relationship of kinship and hometown love. In a sense, it is impossible to talk about the care for "strangers".

During the thirty years since the reform and opening up, China's economy has developed rapidly, and it should be said that it has made glorious achievements in the construction of material civilization, but the construction of spiritual civilization is not as satisfactory as it should be, although as early as 1983 Comrade Deng Xiaoping pointed out: "If we do not strengthen the construction of spiritual civilization, the construction of material civilization will also be damaged and take a wrong turn. " However, when the whole Chinese society enters the market economy tide, the lack of strong spiritual guidance, from the central to local overemphasis on economic development, the short-sighted mentality of everyone "tending to profit and avoiding harm" makes the already very weak social morality face a greater test and impact.

To sum up, the current problem of social morality in China can be said to originate from the poor historical foundation and the misplaced concept of "materialism over spirituality" since the reform and opening.

\subsubsection{Analysis of traffic congestion problem}

Traffic congestion is not only a problem in China, but also exists in cities worldwide, especially in large cities, to varying degrees. As in other countries, one of the major reasons for traffic congestion in Chinese cities is the proliferation of motor vehicles, especially the number of private cars, especially because of the large population base in China, even though the per capita car ownership is much lower than that of developed countries in Europe and the United States, the overall number is amazing, which brings a heavy burden to urban road traffic and causes traffic congestion.

So, does the traffic congestion problem in Chinese cities have its own characteristics? The author believes that there are still its special characteristics, because compared with other developed countries, China's motorization process is developing very fast but late, 
especially the development of private cars should only be the last decade; because the national driving years less, even if the driving skills are good, but in the actual driving process most do not talk about basic manners, and do not know in the vehicle driving to avoid and consciously and strictly comply with the traffic rules, resulting in green light grabbing, lane grabbing. This leads to the frequent occurrence of uncivilized events such as green light grabbing, lane grabbing and random lane changing, which in turn leads to traffic congestion and even traffic safety accidents.

\subsubsection{Analysis of environmental degradation problem}

The current environmental degradation problem is also a global problem, which is mainly manifested in the city level as air pollution, water pollution, solid waste pollution, noise pollution, heat island effect, etc. Among them, in addition to industrial waste gas, the pollution caused by automobile exhaust emission is very serious, and this problem is especially prominent for China at present, as discussed above.

Solid waste pollution for the destruction of the urban environment is mainly manifested in the phenomenon of littering, I have seen many times with my own eyes people throwing garbage in their hands to the roadside, although there are garbage bins next to them.

Noise pollution is mainly manifested as industrial noise pollution, construction noise pollution, traffic noise pollution, etc., for the generation of these pollutants, in general, is the problem of two aspects: First, factory enterprises, construction enterprises, vehicle drivers lack of social conscience, in the production, construction and vehicle driving process ignorant of their own behaviour on the surrounding environment and the noise impact of the crowd; Second, all kinds of protective green space The lack of or unreasonable layout does not play a good role in noise reduction.

\subsection{Analysis of ways to solve social problems}

\subsubsection{The ways to solve social moral problems}

Under the influence of the tide of market economy, the problems of social morality in China's contemporary society exist not only in cities, but also in villages. However, the social and economic bases of cities are naturally different from those of rural areas: firstly, the social ties between people in cities are no longer based on kinship and hometown love, but more from the relationships of colleagues, friends and even passers-by established in work and life; secondly, the economic bases of cities are secondary and tertiary industries, and the relationships between people objectively have more communication needs, sharing relationships, cooperation The economic base of the city is the secondary and tertiary industries.

In response to this characteristic, I believe that to solve the moral problems of urban society, it is actually necessary for the general public to realize the necessity of contacting with the so-called "strangers" who have no blood and country relations, to learn to care for the socalled "strangers", to refuse social indifference, and to rebuild "The old man is as old as the others, the young man is as young as the others." This is a harmonious society. Specifically, we need to help citizens regain their sense of social virtue and provide civic education for urban citizens to meet the needs of urban civil society.

\subsubsection{Ways to solve the problem of traffic congestion}

The solution to urban traffic congestion, which has been agreed upon by many traffic experts throughout the world, is to vigorously develop urban public transportation, and the same applies to Chinese cities, such as the establishment of bus-only lanes and the construction of urban rapid rail transit.

What I would like to emphasize here is the solution to the specificity of China's traffic congestion problem. As mentioned above, the proportion of traffic congestion caused by uncivilized driving behaviours such as scrambling, grabbing and squeezing on Chinese urban roads is high. I note that the German traffic department in its driving theory textbook pointed out that their "end product" is not just "a person who can drive", but must be a "calm, always prudent restraint, rich in cooperation The "end product" is not just "a person who can drive," but a "skilled motorist who is calm, always deliberate, cooperative and environmentally conscious. In fact, these are to emphasize that as a motorist must have a sense of social responsibility, in the process of driving must consider the impact of their driving behaviour on other pedestrians, vehicles and the overall traffic environment. In the author's opinion, it is very important for the solution of China's urban traffic congestion problem to pay attention to the establishment of drivers' road civic-mindedness and educate them to become a qualified urban driving citizen.

In addition, I would like to emphasize that the general public in the air pollution, solid waste pollution, noise pollution in fact also played an undesirable role cannot be ignored, how to solve reduce these adverse effects it boils down to a point is to improve the general public's social conscience, improve environmental awareness, change the uncivilized habits of life, starting from themselves, to reduce the damage to the urban environment.

\subsection{The importance of civic-mindedness and public life}

Reviewing the analysis of the above three major urban social problems, we can clearly see that although each of these three social problems has its own specificity, they also have a significant commonality, that is, they can be solved through the cultivation of civic-mindedness among urban citizens.

How do we understand social civic-mindedness? In the author's opinion, it can be simply understood as the ability to be truly aware of and consider the existence 
and feelings of others when getting along with others and the environment, to minimize the negative impact on the environment, and to live in harmony with the surrounding people and the environment.

Since social ethics is so important for solving social problems, how should we cultivate social ethics among the general public? In the author's opinion, while traditional education is important, such as moral education in schools and family life, a true sense of public morality cannot be formed simply by preaching.

So how should a sense of public morality be cultivated? This can be inferred from social problems, such as how social indifference is formed? People tend to care about their relatives and familiar people, so how to eliminate the divide between strangers in urban society? The author believes that only through more contact, in many contacts (mainly mutual help and communication) to find and feel the beauty of "giving roses to others, hands have fragrance", to eliminate the divide, in order to change the original habit of indifference to "passers-by", the formation of conscious The habit of caring for and taking into account the people around us. So, where and from where should we make contact?

The presence or absence of social ethics is mainly reflected in the public life of the city, so "learning to apply", just as college students need to find internship units for a period of time before entering the workplace, the cultivation of social ethics is also to enable the general public to live together in harmony in public life. Therefore, I believe that the best scenario for cultivating social ethics is the specific urban public life, and the best place for contact is naturally the public space that carries urban public life.

\subsection{Selection of Public Spaces}

Urban public space refers to those outdoor spaces for public use in the daily life and social life of urban residents. It includes streets, squares, residential outdoor areas, parks, sports grounds, etc. ${ }^{[3]}$; so, which public space should be selected for public life scenes to cultivate social civility? The author believes that streets are the most suitable public space because (1) compared to other public land, urban transportation land covers the widest area and has the largest number of users; (2) according to the road network planning standards of large and medium-sized cities ${ }^{[4]}$ (see Table 1), the main carrier of streets - urban secondary roads and feeder roads have the highest density, and compared to other urban public spaces streets have the highest frequency of use and the largest number of users. Here, people's behaviour will be watched by the largest number of people, and uncivilized behaviour will be corrected more or less because of the attention.

Table 1. Density planning index of road network in large cities

\begin{tabular}{|c|c|c|c|c|}
\hline Projects & $\begin{array}{c}\text { Express } \\
\text { way }\end{array}$ & $\begin{array}{c}\text { Main } \\
\text { roads }\end{array}$ & $\begin{array}{c}\text { Secondary } \\
\text { roads }\end{array}$ & $\begin{array}{c}\text { Branch } \\
\text { Road }\end{array}$ \\
\hline $\begin{array}{c}\text { Road network } \\
\text { density } \\
(\mathrm{km} / \mathrm{km} 2)\end{array}$ & $0.4-0.5$ & $0.8-1.2$ & $1.2-1.4$ & $3-4$ \\
\hline
\end{tabular}

\subsection{The uniqueness of street space}

Street is a very broad concept of space, it can be as wide as Beijing Chang'an "Street" Shanghai Century "Avenue", can also be as narrow as hutongs, lanes, alleys [5]. The Principles of Urban Planning defines it as follows: a street is a basic urban linear open space, which not only undertakes the task of transportation, but also provides a place for public activities for urban residents, and different types of streets often have different functional focus.

Although the definition of urban streets may not be as clear as urban roads, it is certain that: as an important public space carrying public life, it has the commonality of general urban public space, suitable as a place to cultivate social morality; at the same time, it has its unique characteristics, these characteristics are not only the most frequently used, the most people use, but also manifested as urban streets. Streets also have the following three unique and important public values.

\subsubsection{Economic value}

The development and construction of commercial buildings on both sides of the city streets, combined with the design of pedestrian walkways, will have a large flow of people, the commercial value is self-evident; from this point of view, compared to other urban public space, in addition to the social value of the carrier of public life, the city streets also have a great economic value, so the development and construction of streets can be a good balance between social and economic benefits. Economic benefits.

\subsubsection{Slow traffic value}

The author believes that, compared to other levels of urban roads, such as expressways and trunk roads, in addition to motorized traffic, more importantly, nonmotorized traffic and pedestrian traffic, two types of slow traffic. Compared with motorized traffic, slow traffic can effectively slow down the current society's too fast pace of work and life, soothe people's nervousness, and help in the process of daily traffic contact communication, public life.

\subsubsection{Landscape value}

As an important public space in the city, compared with other public spaces, it not only carries the prosperity and 
style of an area, but also reflects the unique style and taste of a city, and the current phenomenon of "a thousand cities" in many Chinese cities is largely due to the lack of attention to the continuation of the urban fabric, while the city streets The city street is precisely an important part of the urban fabric; and, the city street combined with its own linear design and the architectural design on both sides is undoubtedly an important part of the urban landscape.

\section{Conclusion}

The author hopes that this paper will clarify the significance of urban street space as a place of public life in the context of rapid urbanization in solving social problems, and its important public value in cultivating social morality; and that it will draw the attention of city government decision-makers and urban planners to protect traditional street space while paying attention to the construction of new and more complete street networks!

\section{References}

1. Zhang X. T., Zhang L. X. (2021) Overview of China's urbanization process and forecast of future urbanization level. Journal of Yunnan Agricultural University (Social Sciences), 15(1): 20 - 25.

2. Tang, L.F. (2011) Social morality: A moral dilemma in contemporary Chinese moral construction. Seeking, 4:117.

3. Wu, Z.Q., Li, D.H. (2010) Principles of urban planning. China Construction Industry Press, Beijing.

4. Ministry of Construction of the People's Republic of China. (1995) GB50220-1995 Urban road traffic planning and design specification. China Standard Publishing House, Beijing.

5. Zhuo, J. (2010) Urban street research and planning design: 50 streets around the world. China Construction Industry Press, Beijing. 